\title{
Treatment Options Available for COVID-19 and an Analysis on Possible Role of Combination of rhACE2, Angiotensin (1-7) and Angiotensin (1-9) as Effective Therapeutic Measure
}

\author{
Shahnawaz Muslim ${ }^{1} \cdot$ Nasrin Nasrin $^{2} \cdot$ Faisal Obaid Alotaibi ${ }^{3} \cdot$ Geeta Prasad $^{4} \cdot$ Shambhu Kumar Singh $^{5} \cdot$ Izhar Alam $^{6}$. \\ Gulam Mustafa $^{3}$
}

Accepted: 10 July 2020 / Published online: 22 August 2020

(C) Springer Nature Switzerland AG 2020

\begin{abstract}
Corona virus disease (COVID-19), caused by SARS-CoV-2, is rapidly spreading all around the world and is posing a threat to mankind. Since SARS-CoV-2 is a novel virus, little is known about it and no effective drug is available for its treatment. While many drugs are being evaluated, an effective therapeutic measure is still lacking. SARS-CoV-2 like SARS-CoV binds with angiotensin-converting enzyme 2 (ACE2) present on human cells. SARS-CoV has been found to downregulate ACE2 and SARS- CoV-2 infection has been found to be associated with increased level of Angiotensin II. Based on these facts, we presume that SARS-CoV-2 like SARS-CoV downregulates ACE2, and in absence/reduced activity of ACE2, level of angiotensin (1-7) and angiotensin (1-9) is decreased while that of angiotensin II is increased and increased level of angiotensin II has been found to correlate with lung injury and viral load. We presume that restoration of normal functioning of renin-angiotensin system with recombinant human angiotensin-converting enzyme 2 (rhACE2), angiotensin (1-7) and angiotensin (1-9) may be an effective therapeutic measure but studies will be required to test this hypothesis and explore its possible role in treatment of COVID-19.
\end{abstract}

Keywords COVID-19 · Angiotensin-converting enzyme $2 \cdot \operatorname{rhACE} 2 \cdot \mathrm{SARS}-\mathrm{CoV}-2 \cdot$ Angiotensin

\section{Introduction}

In December 2019, many cases of pneumonia of unknown etiology were reported from Wuhan, China [1]. Cause of this disease was attributed to a new corona virus. The WHO named this

This article is part of the Topical Collection on Covid-19

Gulam Mustafa

gulampharma@gmail.com

1 Dept. of Surgery, Madhubani Medical College and Hospital, Madhubani, Bihar, India

2 Dept. of Tuberculosis and Chest, Katihar Medical College and Hospital, Karim Bagh, Katihar, Bihar, India

3 College of Pharmacy, Al-Dawadmi Campus, Shaqra University, P.O. Box 11961, Riyadh, Kingdom of Saudi Arabia

4 Samford Superspeciality Hospital, Kokar Chowk, Ranchi, Jharkhand, India

5 Dept. of Surgery, Katihar Medical College and Hospital, Karim Bagh, Katihar, Bihar, India

6 Dept. of Pathology, Katihar Medical College and Hospital, Karim Bagh, Katihar, Bihar, India virus as novel corona virus (nCoV) and the disease as corona virus disease 19 (COVID-19). Later on, the International Committee on Taxonomy of Viruses renamed the virus as severe acute respiratory syndrome corona virus 2 (SARS-CoV-2) due to its genomic similarity with SARS-CoV [2].

SARS-CoV-2 spreads very rapidly, and within a short interval of time, it has spread all around the globe and has put almost the whole globe under lockdown. Several people have died and this number is rapidly increasing. Until date, no effective treatment is available. Treatment options are limited but emerging. To describe the available treatment options and to find a new and effective therapeutic measure, we present a review of drugs available and an analysis on possible role of combination of recombinant human angiotensin-converting enzyme 2 (rhACE2), angiotensin (1-7) and angiotensin (1-9) (AAA) for treatment of COVID-19.

\section{Chloroquine}

Chloroquine is a known anti-malarial drug which also possesses immunomodulatory property and recently has been 
found to have antiviral activity. Probable mechanism of antiviral action includes alteration in endosomal $\mathrm{PH}$ and blockage of viral entry and post entry events like replication, aggregation, transportation and viral release. The immunomodulatory activity acts synergistically with antiviral activity. In vitro study has shown that it has activity against SARS-CoV-2 in Vero E6 cells infected with virus. Wang et al. demonstrated that chloroquine acts at both entry and post entry stage of SARS-CoV-2 infection in Vero E6 cells and EC50 of chloroquine in Vero E6 cells against SARS-CoV-2 is $1.13 \mu \mathrm{M}[3,4]$.

Clinical data also support benefit of chloroquine in patients suffering from SARS-CoV-2 infection. In clinical trial conducted at China with more than 100 patients, the drug has been found to reduce exacerbation of pneumonia, improve lung imaging findings, improve viral clearance and shorten duration of disease in COVID-19 patients suffering from pneumonia [5].

As far as current role of chloroquine in treatment of COVID-19 is concerned, Emergency Use Authorization (EUA) guidelines by the FDA recommend its use in adults or adolescents weighing $50 \mathrm{~kg}$ or more admitted in hospital with COVID-19 and for whom a clinical trial is not available or participation is not feasible [6]. Drug should be used with caution in cardiac patients and in patients with diabetes.

\section{Hydroxychloroquine}

It is an anti-malarial drug which differs from chloroquine because of a hydroxyl group. It also has immunomodulating property and is used in the treatment of autoimmune disorders like rheumatoid arthritis. Like chloroquine, hydroxychloroquine also exhibits antiviral activity against SARS-CoV-2 and mechanism of action is also similar, i.e. alteration of endosomal ph, blockage of virus entry and post entry events.

However, this drug has been found to be more potent than chloroquine as far as the antiviral activity against SARS-CoV2 is concerned. Yao et al. demonstrated that in Vero cells, EC50 for chloroquine was $5.47 \mu \mathrm{M}$ and EC50 for hydroxychloroquine was $0.72 \mu \mathrm{M}$ against SARS-CoV-2 [7].

In clinical studies also, results with hydroxychloroquine have been encouraging. Gauter et al. evaluated the role of hydroxychloroquine on respiratory viral load of SARS-CoV2 and demonstrated that treatment with hydroxychloroquine was significantly associated with viral load reduction [8].

Emergency Use Authorization (EUA) guidelines by the FDA recommends its use in adults or adolescents weighing $50 \mathrm{~kg}$ or more admitted in hospital with COVID-19 and for whom a clinical trial is not available or participation is not feasible [6].

Because of better tolerability and higher potency, hydroxychloroquine appeals to be a preferred drug for
COVID-19 treatment. But, it should be used with caution in cardiac patients as it tends to cause QT prolongation. Simultaneous use of any other drug which causes QT prolongation can be dangerous. One recent study has shown that hydroxychloroquine in combination with azithromycin can lead to serious cardiac rhythm problem and can be fatal [9].

\section{Remdesivir}

Remdesivir is a phosphoramidate prodrug of an adenosine $\mathrm{C}$ nucleoside, developed by Gilead Science Inc. [10]. It is metabolized to active nucleoside triphosphate and acts at RNAdependent RNA polymerase (RdRp) to cause RNA chain termination. It is a broad-spectrum antiviral drug which has activity against many viruses including corona virus. In vitro study on Vero E6 cells has shown potent activity against SARS-CoV-2 with EC50 of $0.77 \mu \mathrm{M}$ at $48 \mathrm{~h}$ [4]. Clinical experience with first case of COVID-19 from the USA showed that treatment with remdesivir was associated with decreased viral load and improved outcome [11]. However, it is too early to draw any final conclusion.

\section{Fapiravir}

Fapiravir is broad-spectrum antiviral drug and an RNAdependent RNA polymerase inhibitor which causes inhibition of viral RNA synthesis. It is used for treatment of influenza. One Chinese trial evaluated the role of fapiravir in COVID-19 cases and demonstrated that fapiravir treatment group was associated with greater clinical recovery rate [12]. At present, very limited data is available for its use in COVID-19 patients.

\section{Lopinavir/Ritonavir}

Lopinavir is a human immunodeficiency virus type 1 (HIV-1) protease inhibitor. Ritonavir is given in fixed-dose combination with lopinavir to increase its plasma concentration through inhibition of cytochrome $\mathrm{p} 450$. Lopinavir/ritonavir combination previously has been found to be effective against SARS-CoV and MERS-CoV [13].

Based on its activity against corona virus, its possible role in treatment of SARS-CoV-2 infection was evaluated. Young et al. from Singapore in a report on 18 patients of COVID-19 described that 5 patients who required oxygen supplementation were treated with lopinavir/ritonavir therapy. Three out of 5 showed improvement and their oxygen requirement was reduced while 2 patients deteriorated and developed respiratory failure. Four out of 5 patients developed adverse drug reaction [14]. An open-label randomized trial comparing lopinavir/ritonavir with standard therapy in admitted patients 
with COVID-19 demonstrated no advantage of lopinavir/ ritonavir over standard care [15]. At present, there is limited data to support role of lopinavir/ritonavir for COVID-19 treatment.

\section{Tocilizumab}

Tocilizumab is a recombinant humanized monoclonal antibody which acts at interleukin-6 (IL-6) receptor and causes its inhibition. IL-6 receptors are present in two forms, soluble IL-6 receptor (sIL-6R) and membrane-bound IL-6 receptor (mIL-6R). IL-6 binds with sIL-6R to form a complex and then binds with gp130 on cell membrane to start inflammatory signal. Tociluzumab binds with both sIL-6R and mIL-6R and causes inhibition of inflammatory response. SARSCoV-2 infection produces inflammatory storm which can lead to death of patients. Tociluzumab by inhibiting IL-6, the driver of cytokine response syndrome (CRS), can reverse the process.

Preliminary data from a Chinese study showed that treatment of severely ill COVID-19 patients with tocilizumab in addition to routine therapy was associated with reduction in oxygen requirement, improvement in CT findings of lung, improvement in peripheral blood picture and reduction in $\mathrm{C}$ reactive protein level, leading to conclusion that tocilizumab is an effective treatment for severely ill COVID-19 patients [16]. At present, clinical data is limited and further studies are required to establish its role in treatment of COVID-19 patients.

\section{Azithromycin}

Azithromycin is a macrolide antibiotic which has been found to have some in vitro activity against viruses like influenza virus and Zika virus; however, there is no in vitro study to suggest its direct action against SARS-CoV-2. It is used in viral infection to prevent super added bacterial infection.

One study with small sample size evaluating the role of hydroxychloroquine on viral load in COVID-19 patient demonstrated that hydroxycloroquine treatment leads to significant viral load reduction and this effect is enhanced by azithromycin [8]. At present, limited data is available to support its role in COVID-19 treatment.

\section{Convalescent Plasma}

Plasma derived from the body of a person who has recovered from a disease is called convalescent plasma. When plasma is derived from the body of a person who has recovered from an infectious disease, it is supposed that the plasma contains antibody against that particular pathogen from which the recovered person was suffering. This antibody-containing plasma can be transferred to another person suffering from the same pathogen in order to target the pathogen. Previous experiences with convalescent plasma for treatment of H1N1 influenza and Ebola virus infection have been encouraging.

One study in China evaluated the role of convalescent plasma in SARS-CoV-2 and demonstrated that 5 critically ill patients of COVID-19 with features of ARDS were given convalescent plasma and it was found that their body temp decreased, SOFA score decreased, Pao2/Fio2 improved, viral load decreased/became negative and all patients became stable [17]. Risk of convalescent plasma transfusion includes transmission of infection and immunological reactions.

\section{Heparin}

The International Society on Thrombosis and Haemostasis (ISTH) interim guidance recommends the use of prophylactic low molecular weight heparin (LMWH) in severe COVID-19 patients [18]. The therapeutic effect of LMWH showed a signficant reduction $(p=0.029)$ in martality $(40 \%)$ in the treatment group with coagulopathy and treated with heparin compared to the treatment group without it (64.2\%) [19]. A recent study demonstrated the interaction between the SARSCoV-2 spike S1 protein receptor-binding domain and heparin, suggesting the development of heparin-based therapeutics [20]. Similarly, increasing levels of d-dimer were related to increasing mortality in non-heparin-treated patients. Heparin exhibits anti-inflammatory effects by neutralizing damageassociated molecular patterns (DAMPs) to protect the endothelial cells by reducing the toxicity of histones on endothelial tight junctions, and decrease lung oedema and vascular leakage [21].

\section{Anti-platelet Therapies}

Patient debilitation from severe COVID-19 may pose challenges in administering routine cardiovascular medications, ranging from anti-platelet therapy to betablockers, and may put patients with or at risk of ischemic heart disease or heart failure at risk of further deterioration of their clinical condition. The global reports indicate that hospitalized critical patients with COVID-19 often develop abnormalities compatible with hypercoagulability and a clinically elevated prevalence of thromboembolic [22]. Zhang and co-worker reported deep vein thrombosis (DVT) and pulmonary embolism (PE), thrombosis in extracorporeal circuits and arterial thrombosis associated with COVID-19 [23]. Although platelets may be involved in the response of local and systemic thromboembolism in COVID-19 coagulopathy, the addition of platelet inhibitor 
to unfractionated heparin or LMWH in therapeutic doses will increase the possibility of bleeding [24]. The microvascular thrombosis, DVT and pulmonary artery thrombosis are caused by abnormally high levels of clotting factor and the absence of normal vascular endothelial protective effects. But the role of platelet activation in this process is less well defined and not clearly implicated yet.

\section{Corticosteroids}

Role of corticosteroids is controversial because at one end it may inhibit the inflammatory response and have an overall beneficial effect while at other end it may predispose to secondary infection and delayed viral clearance.

One study from China reported that treatment of COVID19 patients with ARDS on treatment with methyl prednisolone showed a decrease in risk of death. However, authors also suggested a double-blind randomized trial to validate the result [25]. Since corticosteroid is a double-edged sword, its use should be individualized.

\section{Nitazoxanide}

Nitazoxanide, originally developed as antiprotozoal agent, is a broad-spectrum antiviral drug. Its active metabolite 'tizoxanide' has activity against wide range of viruses like influenza virus, parainfluenza virus, corona viruses, hepatitis $\mathrm{B}$ and $\mathrm{C}$ viruses and many other viruses.

Broad range of its antiviral activity is probably because of the fact that, in place of direct action against virus, it acts on host-regulated pathways of viral replication which may include interferon or mTORC1 signalling pathway $[26,27]$.

As far as its role against SARS-CoV-2 is concerned, in vitro study has demonstrated a potent antiviral activity against SARS-CoV-2 (EC50 $=2.12 \mu \mathrm{M}$ in Vero E6 cells) [4]. However, a clear-cut role in treatment of COVID-19 is not established.

\section{Leronlimab}

Leronlimab is humanized monoclonal antibody which inhibits chemokine receptor CCR5. It is an investigational agent in treatment of COVID-19. In a clinical study involving eight critically ill COVID-19 patients, treatment with leronlimab was associated with improvement of immunological markers and trends towards normalization of CD4/CD8 ratio [28]. Further research is being carried out to establish its role in treatment of COVID-19 patients.

\section{Ribavirin}

Ribavirin is an antiviral drug, a guanosine analogue which causes inhibition of viral RNA synthesis.

In vitro study has demonstrated that ribavirin has antiviral activity against SARS-COV-2 (EC50 of $109.5 \mu \mathrm{M})$ and is several times less potent than remdesivir [4]. Previously it has been used against respiratory syncytial virus and hepatitis $\mathrm{C}$ virus. Dose required for treatment of SARS was associated with significant toxicity [29].

Because of its low potency against SARS-CoV-2 and significant associated toxicity, it is not a good choice for consideration in cases of COVID-19. However, Chinese guidelines recommend ribavirin along with lopinavir/ ritonavir or interferon alfa as a treatment option for patients of COVID-19.

\section{Analysis on Possible Role of Combination of Soluble rhACE2, Angiotensin (1-7) and Angiotensin (1-9) for Treatment of COVID-19}

SARS-CoV-2 like SARS-CoV uses ACE2 as receptor for infecting human cells [30]. After binding with membranebound ACE2 through S-protein, the virus transfers its RNA into human cells, which undergoes translation to produce new viral particles. Studies have shown that SARS-Co-V downregulates the ACE2 [31] and SARS-CoV-2 infection is associated with increased level of angiotensin II [32]. We presume that binding of viral S-protein with ACE2 present on cell leads to downregulation of ACE2, as a result of which ACE2 activity decreases and an imbalance in renin-angiotensin system takes place. In absence/ reduced level of activity of ACE2, angiotensin 1 is predominantly converted into angiotensin II while conversion of angiotensin 1 to angiotensin (1-9) and angiotensin II to angiotensin (1-7) is impaired. As a result of this change, level of pro-inflammatory angiotensin II rises and that of anti-inflammatory angiotensin (1-7) and angiotensin (1-9) decreases [33].

Increased level of angiotensin II has been found to correlate with lung injury and viral load [32]. Administration of rhACE2 may help to restore the function of downregulated ACE2 and administration of angiotensin 1-7 and angiotensin 1-9 may further help in restoration of normal functioning of renin-angiotensin system by antagonizing the effect of abnormally increased angiotensin II. Strict monitoring and titration of doses will be required to maintain homeostasis and obtain the desired result. However, this is a hypothesis and needs to be tested to know the exact result and assess the risk benefit ratio. 


\section{Conclusion}

Until date, there is no effective treatment against COVID-19. Research is on and multiple drugs are being evaluated. Some of them have shown encouraging results but success is still not at hand. Since downregulation of ACE2 and imbalance of RAS plays an important role in pathogenesis of COVID-19, we feel that restoration of RAS with the use of combination of rhACE2, angiotensin (1-7) and angiotensin (1-9) may be an effective therapeutic measure. However, studies are required to test this hypothesis and know the real outcome and assess the associated risk.

\section{Compliance with Ethical Standards}

Conflict of Interest The authors declare that they have no conflict of interest.

Ethical Approval No required

Informed Consent Not required

\section{References}

1. Lu H, Stratton CW, Tang YW. Outbreak of pneumonia of unknown etiology in Wuhan China: the mystery and the miracle. J Med Virol. 2020;92:401-2. https://doi.org/10.1002/jmv.25678.

2. Gorbalenya AE, Baker SC, Baric RS, de Groot RJ, Drosten C, Gulyaeva AA, et al. Severe acute respiratory syndrome-related coreonavirus: the species and itsviruses-a statement of the Coronavirus Study Group. bioRxiv. 2020. https://doi.org/10.1101/ 2020.02.07.937862.

3. Vincent MJ, Bergeron E, Benjannet S, Erickson BR, Rollin PE, Ksiazek TG, et al. Chloroquine is a potent inhibitor of SARS coronavirus infection and spread. Virol J. 2005;2:69. https://doi.org/10. 1186/1743-422X-2-69.

4. Wang M, Cao R, Zhang L, Yang X, Liu J, Xu M, et al. Remdesivir and chloroquine effectively inhibit the recently emerged novel coronavirus (2019-nCoV) in vitro. Cell Res. 2020;30:269-71. https:// doi.org/10.1038/s41422-020-0282-0.

5. Gao J, Tian Z, Yang X. Breakthrough: chloroquine phosphate has shown apparent efficacy in treatment of COVID-19 associated pneumonia in clinical studies. Biosci Trends. 2020;14(1):72-3. https://doi.org/10.5582/bst.2020.01047.

6. US Food and Drug Administration. Fact sheet for health care providers emergency use authorization (EUA) of chloroquine phosphate supplied from the strategic national stockpile for treatment of COVID-19 in certain hospitalized patients. From FDA website (https://www.fda.gov/media/136535/download

7. Yao X, Ye F, Zhang M, et al. In vitro antiviral activity and projection of optimized dosing design of hydroxychloroquine for the treatment of severe acute respiratory syndrome coronavirus 2 (SARS-CoV-2). Clin Infect Dis. 2020. https://doi.org/10.1093/cid/ ciaa237.

8. Gautret P, Lagier J, Parola P, et al. Hydroxychloroquine and azithromycin as a treatment of COVID-19: results of an openlabel non-randomized clinical trial. Int J Antimicrob Agents. 2020;20:105949. https://doi.org/10.1016/j.ijantimicag.2020. 105949 .
9. Lane JCE, Weaver J, Kosta K, et al. Safety of hydroxychloroquine, alone and in combination with azithromycin, in light of rapid widespread use for COVID-19: a multinational, network cohort and selfcontrolled case series study. medRxiv. https://doi.org/10.1101/ 2020.04.08.20054551.

10. Siegel D, Hui HC, Doerffler E, Clarke MO, Chun K, Zhang L, et al. Discovery and synthesis of a phosphoramidate prodrug of a pyrrolo[2,1-f] [triazin-4- amino] adenine c-nucleoside (GS-5734) for the treatment of Ebola and emergingviruses. J Med Chem. 2017;60:1648-61. https://doi.org/10.1021/acs.jmedchem.6b01594.

11. Holshue ML, DeBolt C, Lindquist S, Lofy KH, Wiesman J, Bruce $\mathrm{H}$, et al. First case of 2019 novel coronavirus in the United States. N Eng1 J Med. 2020;382:929-36. https://doi.org/10.1056/ NEJMoa2001191.

12. Chen C, Huang J, Cheng Z, et al. Favipiravir versus arbidol for COVID-19: a randomized clinical trial. medRxiv. 2020. https:// doi.org/10.1101/2020.03.17.20037432.

13. Ratia K, Pegan S, Takayama J, Sleeman K, Coughlin M, Baliji S, et al. A noncovalent class of papain-like protease/deubiquitinase inhibitors blocks SARS virus replication. PNAS. 2008;105(42): 16119-24. https://doi.org/10.1073/pnas.0805240105.

14. Young BE, Ong SWX, Kalimuddin S, Low JG, Tan SY, Loh J, et al. Epidemiologic features and clinical course of patients infected with SARS-CoV-2 in Singapore. Jama. 2020;323(15):1488-94. https://doi.org/10.1001/jama.2020.3204.

15. Cao B, Wang Y, Wen D, Liu W, Wang J, Fan G, et al. A trial of lopinavir-ritonavir in adults hospitalized with severe Covid-19. N Engl J Med. 2020;382:1787-99. https://doi.org/10.1056/ NEJMoa2001282.

16. Xu X, Han M, Li T, Sun W, Wang D, Fu B, et al. Effective treatment of severe COVID-19 patients with tocilizumab. PNAS. 2020;17(20):10970-5. https://doi.org/10.1073/pnas.2005615117.

17. Shen C, Wang Z, Zhao F, Yang Y, Li J, Yuan J, et al. Treatment of 5 critically ill patients with COVID-19 with convalescent plasma. JAMA. 2020;323(16):1582-9. https://doi.org/10.1001/jama.2020. 4783.

18. Thachil J, Wada H, Gando S, et al. ISTH interim guidance on recognition and management of coagulopathy in COVID-19. J Thromb Haemost. 2020;18:1023-6. https://doi.org/10.1111/jth. 14810

19. Tang N, Bai H, Chen X, Gong J, Li D, Sun Z. Anticoagulant treatment is associated with decreased mortality in severe coronavirus disease 2019 patients with coagulopathy. J Thromb Haemost. 2020;18:1094-9.

20. Microft-West C, Su D, Elli S, Guimond S, Miller G, Turnbull J, et al. The 2019 coronavirus (SARS-CoV-2) surface protein (Spike) $\mathrm{S} 1$ receptor domain undergoes conformational change upon heparin binding. bioRxiv. 2020. https://doi.org/10.1101/2020.02.29. 971093.

21. Liu Y, Mu S, Li X, Liang Y, Wang L, Ma X. Unfractionated heparin alleviates sepsis-induced acute lung injury by protecting tight junctions. J Surg Res. 2019;238:175-85.

22. Danzi GB, Loffi M, Galeazzi G, Gherbesi E. Acute pulmonary embolism and COVID-19 pneumonia: a random association? Eur Heart J. 2020;41:1858

23. Zhang Y, Xiao M, Zhang S, Xia P, Cao W, Jiang W, et al. Coagulopathy and antiphospholipid antibodies in patients with Covid-19. N Engl J Med. 2020;382:e38.

24. Hobl EL, Derhaschnig U, Firbas C, Schoergenhofer C, Schwameis M, Jilma B. Reversal strategy in antagonizing the P2Y12 -inhibitor ticagrelor. Eur J Clin Investig. 2013;43:1258-61.

25. Wu C, Chen X, Cai Y, Xia J', Zhou X, Xu S, et al. Risk factors associated with acute respiratory distress syndrome and death in patients with corona virus disease 2019 pneumonia in Wuhan, China. JAMA Intern Med. 2020;180:934. https://doi.org/10.1001/ jamainternmed.2020.0994. 
26. Rossignol JF. Nitazoxanide: a first-in-class broad-spectrum antiviral agent. Antivir Res. 2014;110:94-103.

27. Lam KKY, Zheng X, Forestieri R, Balgi AD, Nodwell M, Volett S, et al. Nitazoxanide stimulates autophagy and inhibits mTORC1 signaling and intracellular proliferation of Mycobacterium tuberculosis. PLoS Pathog. 2012;8:e1002691. https://doi.org/10. 1371/journal.ppat.1002691.

28. CytoDyn, Press release. Treatment with CytoDyn's leronlimab indicates significant trend toward immunological restoration in severely ill COVID-19 patients. CytoDyn Inc. 2020.

29. Tan EL, Ooi EE, Lin CY, et al. Inhibition of SARS coronavirus infection in vitro with clinically approved antiviral drugs. Emerg Infect Dis. 2004;10(4):581-6.

30. Zhou P, Yang XL, Wang XG, Hu B, Zhang L, Zhang W, et al. A pneumonia outbreak associated with a new coronavirus of probable bat origin. Nature. 2020;579:270-3. https://doi.org/10.1038/ s41586-020-2012-7.
31. Kuba K, Imai Y, Rao S, Jiang C, Penninger JM. Lessons from SARS: control of acute lung failure by the SARS receptor ACE2. J Mol Med. 2006;84(10):814-20. https://doi.org/10.1007/s00109006-0094-9.

32. Liu Y, Yang Y, Zhang C, Huang F, Wang F, Yuan J, et al. Clinical and biochemical indexes from $2019-\mathrm{nCoV}$ infected patients linked to viral loads and lung injury. Sci China Life Sci. 2020;63(3):364 74. https://doi.org/10.1007/s11427-020-1643-8.

33. Mancini E, Jonas F. View: "Scorched Earth" strategy: the RAS as possible target for treating COVID-19 patients with a combination of three approved pharmaceutical agents. Basel. 2020. https://doi. org/10.13140/RG.2.2.35010.94400.

Publisher's Note Springer Nature remains neutral with regard to jurisdictional claims in published maps and institutional affiliations. 